\title{
Motor skills in adolescents with low birth weight
}

\author{
K A I Evensen, T Vik, J Helbostad, M S Indredavik, S Kulseng, A-M Brubakk
}

Arch Dis Child Fetal Neonatal Ed 2004;89:F451-F455. doi: 10.1136/adc.2003.037788

See end of article for authors' affiliations .....................

Correspondence to: Dr Evensen, Department of Laboratory Medicine, Children's and Women's Health, St Olavs Hospital, $\mathrm{N}-7006$ Trondheim, Norway; karianne.i. evensen@medisin.ntnu.no

Accepted

10 November 2003

\begin{abstract}
Background: Minor motor problems have been reported in low birthweight children, but few studies have assessed motor skills in adolescents.

Objective: To examine the prevalence of motor problems in adolescents with low birth weight.

Method: Fifty four very low birthweight (VLBW: birth weight $\leqslant 1500 \mathrm{~g}$ ), 59 term small for gestational age (SGA: birth weight $<10$ th centile), and 83 control (birth weight $\geqslant 10$ th centile at term) children were assessed with the Movement assessment battery for children (Movement $A B C$ ) at the age of 14 in a population based study.

Results: One in four VLBW children (odds ratio (OR) 9.3, 95\% confidence interval (CI) 2.5 to 34.5) and one in six SGA children (OR 4.7, 95\% Cl 1.2 to 18.4) had motor problems compared with controls (3.7\%). There were no sex differences in motor problems in the VLBW group, and the increased risk was consistent across the continuum of the Movement ABC. For SGA children, the increased risk of motor problems was particularly in manual dexterity in boys.

Conclusion: VLBW and SGA adolescents have increased risk of motor problems compared with control children.
\end{abstract}

L ow birth weight is the most important risk factor for perinatal death and morbidity, ${ }^{1}$ and may result from short gestation and/or intrauterine growth retardation. ${ }^{2}$ Advances in prenatal care, obstetrics and neonatal medicine over the last 20 years have improved short term prognosis, ${ }^{3}$ but at the same time there is increasing concern about long term outcome for these children. ${ }^{4-6}$

Children with a birth weight $\leqslant 1500$ g (very low birth weight: VLBW) are especially at risk of later developmental problems. These children have an increased risk of cerebral palsy $^{3} 7$ and other major handicaps, such as blindness, deafness, and subnormal intelligence. ${ }^{3}$ Motor problems seem to be the most common minor impairment in VLBW children. ${ }^{8}$ Several studies have reported an increased prevalence of motor problems in VLBW children at preschool ${ }^{9-13}$ and school age. ${ }^{14-18}$ There have been few reports on motor skills in VLBW adolescents. ${ }^{19}{ }^{20}$ However, a high prevalence of motor problems in 12-13 year old VLBW children has been reported. ${ }^{20}$

Children who have been growth retarded in utero are usually diagnosed by having a low birth weight adjusted for gestational age (small for gestational age: SGA). SGA infants born at term are at some risk of later developmental problems, as indicated by a slightly increased risk of cerebral palsy $^{21}$ and minimal neurological dysfunction. ${ }^{22}$ Studies on motor problems among younger SGA children born at term have shown inconsistent results, ${ }^{23-25}$ and we are not aware of such studies in adolescents.

In this study, we wanted to examine whether VLBW and term SGA children have an increased prevalence of motor problems in adolescence compared with control children.

\section{MATERIAL AND METHODS}

\section{Study design and study population}

This is a follow up study of two groups of low birthweight children: (a) preterm VLBW (birth weight $\leqslant 1500 \mathrm{~g}$ ); (b) term SGA (birth weight $<10$ th centile). Details of the study are presented in the preceding article. ${ }^{26}$

A total of 54 VLBW (29 boys, 25 girls), 59 SGA (27 boys, 32 girls), and 83 control ( 35 boys, 48 girls) children had a motor assessment. Table 1 shows gestational age and anthropometric measurements. Fifteen VLBW, 33 SGA, and 27 control children did not consent to participation. There were no significant differences in maternal age, duration of pregnancy, the infants' birth weight, body length, and head circumference between those who participated and those who did not consent to participate in any of the groups.

\section{Methods}

Each child was tested with the Movement assessment battery for children (Movement $\mathrm{ABC})^{27}$ by the first author (physiotherapist), who was blinded to the adolescent's group assignment. The Movement ABC consists of eight items, scored between 0 (optimal score) and 5 and grouped as three subscores: manual dexterity, ball skills, and static/dynamic balance. Scores $<5$ th centile indicate definite motor problems. ${ }^{27}$ We used the highest age band, designed for $11-$ 12 year old children. As the study population was examined at age 14, we used the 5th centile derived from the control group, corresponding to a total score of 14, well in accordance with the 5 th centile in the manual.

In this study, intratester reliability with respect to timing and counting was assessed by videotaping 34 children. The intraclass correlation (ICC 1.1) ${ }^{28}$ was found to be 0.9996 for timing (item 1) and 0.9935 for counting (item 4).

Five children (four VLBW children, one control) were not able to complete all test items. Analysis on item scores and subscores were performed by both using all available data and excluding subjects with incomplete data.

Cerebral palsy was diagnosed and classified as diplegia, hemiplegia, or quadriplegia by project paediatricians. ${ }^{29}$

An estimate of intelligence quotient $\left(\mathrm{IQ}_{\mathrm{est}}\right)$ was calculated using four subscales of Wechsler intelligence scales (WISCIII). ${ }^{26}{ }^{30}$ We defined "low IQest" as below 2 SDs of the control group mean value.

Socioeconomic status was calculated according to Hollingshead's two factor index of social position. ${ }^{2631}$

Abbreviations: $\mid Q_{\text {est, }}$ estimate of intelligence quotient; Movement $A B C$, Movement assessment battery for children; SGA, small for gestational age; VLBW, very low birth weight 


\section{What is already known on this topic}

- VLBW children have increased risk of motor problems

- Studies on term SGA children have shown inconsistent results

\section{What this study adds}

- Prevalence of motor problems in VLBW and term SGA adolescents, based on Movement ABC

- Description of motor problems in these groups, highlighting:

- Low birthweight adolescents have increased risk of motor problems

- VLBW adolescents have widespread motor problems

- SGA boys have specific problems in manual dexterity

\section{Ethics}

The regional committee for medical research ethics approved the study protocol. Written informed consent was obtained from both adolescent and parents.

\section{Statistical analysis}

SPSS 11.5.1 was used for data analysis, and a significance level of 0.05 was chosen. Three-group comparisons were made using one way analysis of variance for variables with a normal distribution, and Kruskal-Wallis for variables with a non-normal distribution. If a significant difference was found between the three groups, two-group comparisons were made by Scheffe's post hoc test for variables with a normal distribution and Mann-Whitney U test for variables with a non-normal distribution. The $\chi^{2}$ test was used to analyse differences in proportions between groups.

Odds ratio (OR) was calculated and used as an estimate of the relative risk of motor problems for children with low birth weight compared with the control group. We applied bivariate logistic regression analysis for variables associated with group and/or outcome measures to calculate adjusted odds ratios, in order to control for possible confounding factors. ${ }^{32}$

\section{RESULTS}

At follow up, VLBW and SGA children were shorter, lighter, and had smaller head circumference than controls, whereas

Table 1 Gestational age and anthropometric measurements at birth in two groups of low birthweight children compared with a control group in a follow up study

\begin{tabular}{llll}
\hline & $\begin{array}{l}\text { VLBW } \\
(\mathbf{n}=54)\end{array}$ & $\begin{array}{l}\text { SGA } \\
(\mathbf{n}=59)\end{array}$ & $\begin{array}{l}\text { Control } \\
(\mathbf{n}=83)\end{array}$ \\
\hline Gestational age (weeks) & $28.9(2.7)^{*}$ & $39.4(1.1)$ & $39.6(1.2)$ \\
Birth weight (g) & $1179(234)^{*}$ & $2934(235)^{*}$ & $3691(459)$ \\
Body length (cm) $\dagger$ & $38.5(2.8)^{*}$ & $48.4(2.0)^{*}$ & $51.0(1.8)$ \\
Head circumference $(\mathrm{cm}) \neq$ & $26.9(2.5)^{*}$ & $33.8(1.2)^{*}$ & $35.4(1.1)$ \\
\hline
\end{tabular}

Values are mean (SD).

${ }^{*} p<0.001 v$ controls (gestational age and birth weight were the selection criteria, and differed by definition from controls).

†Body length was only measured for 35 children in the VLBW group.

tHead circumference was only measured for 41 children in the VLBW group.

VLBW, Very low birth weight; SGA, small for gestational age.
Table 2 Age, height, weight, body mass index, head circumference, and socioeconomic status in two groups of low birthweight children compared with a control group at 14 years of age

\begin{tabular}{llll}
\hline & $\begin{array}{l}\text { VLBW } \\
(\mathbf{n}=54)\end{array}$ & $\begin{array}{l}\text { SGA } \\
(\mathbf{n}=59)\end{array}$ & $\begin{array}{l}\text { Control } \\
(\mathbf{n}=83)\end{array}$ \\
\hline Age (years) & $14.1(0.3)$ & $14.2(0.3)$ & $14.2(0.3)$ \\
Height $(\mathrm{cm})$ & $161(9.3)^{* * *}$ & $164(7.4)^{*}$ & $167(7.6)$ \\
Weight $(\mathrm{kg})$ & $49.9(12.1)^{* *}$ & $52.2(8.5)^{*}$ & $56.8(10.7)$ \\
Body mass index $\left(\mathrm{kg} / \mathrm{m}^{2}\right)$ & $19.1(3.9)$ & $19.5(2.9)$ & $20.2(3.0)$ \\
Head circumference $(\mathrm{cm})$ & $54.3(1.9)^{* * *}$ & $54.7(2.0)^{* * *}$ & $55.9(1.5)$ \\
Socioeconomic status & $3.2(1.3)^{*}$ & $3.4(1.3)$ & $3.8(1.1)$ \\
\hline
\end{tabular}

Values are mean (SD).

${ }^{*} \mathrm{p}<0.05,{ }^{* *} \mathrm{p}<0.01,{ }^{* * *} \mathrm{p}<0.001 v$ controls.

VLBW, Very low birth weight; SGA, small for gestational age.

body mass index did not differ between the three groups (table 2). Socioeconomic status was lower in the VLBW group than in the control group. There were no differences between groups with regard to age, sex, or handedness.

Six $(11 \%)$ VLBW children (four diplegia, one hemiplegia, one quadriplegia) and one (2\%) SGA child (diplegia) had cerebral palsy. Four children with cerebral palsy completed all test items. Ten (18.5\%) VLBW, four (6.8\%) SGA, and three (3.6\%) control children had a low IQ est.

The VLBW group had higher mean values than the control group in total $\mathrm{ABC}$ score and all subscores (table 3). This persisted after the exclusion of children with cerebral palsy, low $\mathrm{IQ}_{\text {est }}$, and/or children with incomplete test results from the analysis (data not shown). There were no differences in mean subscores or total $\mathrm{ABC}$ score between the SGA group and the control group.

Boys had poorer manual dexterity than girls in both the SGA and control groups (table 4). This sex difference was not found in the VLBW group. There were no differences in ball skills, balance, and total ABC scores between boys and girls in the VLBW or the control group. In the SGA group, boys scored better than girls in ball skills, but worse in balance and total $\mathrm{ABC}$ score.

Thirteen of 50 (26\%) VLBW children (OR 9.3, 95\%CI 2.5 to $34.5 v$ controls), and nine of 59 (15.3\%) SGA children (OR $4.7,95 \%$ CI 1.2 to $18.4 v$ controls) had motor problems compared with three of $82(3.7 \%)$ control children (table 5$)$. After exclusion of the children with cerebral palsy, the risk of a total $\mathrm{ABC}$ score $<5$ th centile was slightly reduced for both VLBW (OR 7.1, 95\%CI 1.8 to 27.4) and SGA children (OR 4.2, 95\%CI 1.1 to 16.6). After exclusion of children with low $\mathrm{IQ}_{\mathrm{est}}$, the results showed a small reduction in risk of motor problems in the VLBW (OR 6.1,95\%CI 1.5 to 24.6) and the SGA group (OR 3.7, 95\%CI 0.9 to 15.0 ).

Compared with the control children, the VLBW children showed poorer skills in both manual dexterity and balance, and the SGA children showed an increased risk of poor manual dexterity. The OR for the subscores remained essentially the same after exclusion of children with cerebral palsy, low IQ est $_{\text {, }}$ and the children who did not complete the whole test (data not shown).

Weight and socioeconomic status at 14 years of age were the only factors associated with both birthweight group and outcome variables; higher weight and lower socioeconomic status were associated with poorer balance and total ABC score. When socioeconomic status was included in the logistic regression analysis, the risk of motor problems was unchanged in the VLBW group and slightly reduced in the SGA group (OR 4.0, 95\%CI 1.0 to 15.9). When weight was included in the logistic regression analysis, the risk of poor balance increased in both low birthweight groups (table 5). Even though weight was not associated with the other 
Table 3 Results of Movement assessment battery for children (Movement ABC) for two groups of low birthweight children compared with a control group

\begin{tabular}{|c|c|c|c|}
\hline & VLBW & SGA & Control \\
\hline Total Movement $A B C$ score $(n=50 / 59 / 82)$ & $11.0(7.8)^{* \star *}$ & $7.3(5.9)$ & $6.3(4.4)$ \\
\hline Manual dexterity subscore $(n=52 / 59 / 82)$ & $2.5(2.9)^{* *}$ & $2.2(3.1)$ & $1.2(1.6)$ \\
\hline Turning pegs & $1.1(1.4)$ & $1.1(1.5)$ & $0.9(1.2)$ \\
\hline Cutting out elephant & $1.2(1.6)^{* * *}$ & $0.8(1.5)$ & $0.3(0.7)$ \\
\hline Flower trail & $0.5(1.0)^{\star *}$ & $0.3(0.9)^{*}$ & $0.1(0.4)$ \\
\hline Ball skills subscore $(n=51 / 59 / 83)$ & $2.7(2.5)^{\star *}$ & $1.3(1.6)$ & $1.6(1.9)$ \\
\hline One hand catch & $1.4(1.6)^{*}$ & $0.4(0.9)$ & $0.7(1.1)$ \\
\hline Throwing at target & $1.3(1.5)$ & $0.9(1.0)$ & $0.9(1.2)$ \\
\hline Static/dynamic balance subscore $(n=50 / 59 / 83)$ & $5.7(4.0)^{* *}$ & $3.8(3.2)$ & $3.5(2.9)$ \\
\hline Two board balance & $3.2(1.9)$ & $2.6(1.9)$ & $2.5(2.0)$ \\
\hline Jumping and clapping & $1.9(1.9)^{* *}$ & $0.9(1.4)$ & $0.9(1.3)$ \\
\hline Walking backwards & $0.7(1.5)^{* *}$ & $0.3(1.0)^{*}$ & $0.1(0.6)$ \\
\hline \multicolumn{4}{|c|}{$\begin{array}{l}\text { Values are mean (SD). } \\
{ }^{*} p<0.05,{ }^{* *} p<0.01,{ }^{* * *} p<0.001 v \text { controls. } \\
\text { VLBW, Very low birth weight; SGA, small for gestational age. }\end{array}$} \\
\hline
\end{tabular}

subscores or the total $\mathrm{ABC}$ score, we also adjusted for weight in these scores. This increased the risk of poor manual dexterity and overall motor problems in the SGA group. When children with cerebral palsy and/or low IQest were excluded, the results changed slightly (table 5 ).

Factors associated with birthweight group (height and head circumference) or with one or more of the outcome measures (sex, handedness, and body mass index) were also separately included in logistic regression analysis as potential confounders. The only factor contributing to a major change in OR was height, and, after adjustment for height, the risk of poor manual dexterity increased in the SGA group (OR 12.7, $95 \%$ CI 2.7 to 60.1 ).

The increased risk of motor problems in the VLBW group was essentially the same for boys and girls. In the SGA group, the increased risk was found only among boys (table 6). This was most pronounced for poor manual dexterity, where SGA boys showed five times the risk of control boys (OR 5.2, $95 \%$ CI 1.2 to 21.6 ).

\section{DISCUSSION}

In this study, we found that one in four VLBW children and one in six SGA children had motor problems at 14 years of age. For VLBW children the increased risk was consistent among boys and girls, whereas for SGA children the risk was particularly high for boys with respect to manual dexterity. Analyses excluding children with cerebral palsy and/or low

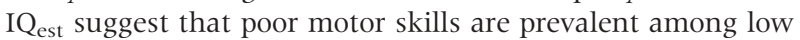
birthweight children without known physical and/or mental deficiencies.

Table 4 Results of the Movement assessment battery for children (Movement $A B C$ ) for boys and girls in two groups of low birthweight children and a control group

\begin{tabular}{lllll}
\hline & Group & Boys & Girls & p Value \\
\hline Total Movement & VLBW $(n=50)$ & $10.6(9.2)$ & $11.5(5.8)$ & 0.227 \\
ABC score & SGA $(n=59)$ & $9.3(7.0)$ & $5.6(4.1)$ & 0.048 \\
Manual dexterity & Control $(n=83)$ & $6.8(4.5)$ & $6.0(4.3)$ & 0.658 \\
subscore & SGW $(n=52)$ & $2.5(3.1)$ & $2.5(2.8)$ & 0.598 \\
& Control $(n=82)$ & $3.8(3.7)$ & $0.9(1.6)$ & 0.000 \\
Ball skills & VLBW $(n=51)$ & $2.4(1.9)$ & $0.8(1.2)$ & 0.001 \\
subscore & SGA $(n=59)$ & $1.0(1.6)$ & $1.6(1.5)$ & 0.291 \\
& Control $(n=83)$ & $1.3(1.9)$ & $1.8(1.9)$ & 0.091 \\
Static/dynamic & VLBW $(n=50)$ & $5.7(4.5)$ & $5.7(3.5)$ & 0.710 \\
balance subscore & SGA $(n=59)$ & $4.6(3.3)$ & $3.1(2.9)$ & 0.053 \\
& Control $(n=83)$ & $3.6(2.8)$ & $3.5(2.9)$ & 0.904 \\
\hline \multirow{2}{*}{ Values are mean (SD). } \\
VLBW, Very low birth weight; SGA, small for gestational age.
\end{tabular}

The 10th centile definition of SGA is crude, and a certain proportion of normal small infants could have been classified as SGA, whereas some infants who may have been growth retarded in utero could have been classified as controls. Nonetheless, we found that the SGA group had a fivefold increased risk of motor problems compared with the control group. If SGA children were classified as controls, or vice versa, this would probably have resulted in smaller differences between the groups. The VLBW children were classified according to a birth weight $\leqslant 1500 \mathrm{~g}$. We are aware that some of the children in the VLBW group may have been growth retarded. However, they were all born preterm, and we have chosen to treat them as a group in this study as a contrast with the low birthweight children born at term.

The reason why 75 adolescents $(28 \%)$ did not want to participate in this study is not known. We found, however, no significant differences between mothers and children who participated and those who did not. It is therefore unlikely that the results are due to selection bias.

Poor growth has been described in $\mathrm{VLBW}^{33-35}$ and SGA adolescents, ${ }^{36}$ and was also found for the VLBW and the SGA adolescents in our study compared with the controls. Weight and partly height were identified as possible confounding factors of the association between low birth weight and motor problems. Higher weight and height seemed to increase the risk of motor problems. When we adjusted for these factors, the relative risk of motor problems in the two low birthweight groups was even higher. Thus the increased risk of motor problems in VLBW and SGA children cannot be explained by poor postnatal growth.

Our finding of a high prevalence of motor problems in VLBW children is consistent with the literature. Most studies have examined younger children and have found that 6-8 year old VLBW children have worse scores on the Movement ABC than controls. ${ }^{14-17}$ Few studies have examined motor problems in adolescents. Powls et al ${ }^{20}$ found that $34 \%$ of $12-$ 13 year old children with a birth weight $<1251 \mathrm{~g}$ scored $<5$ th centile on the Movement ABC. This may be well comparable to the finding in our study, considering that our VLBW group is defined by a birth weight $\leqslant 1500 \mathrm{~g}$.

We are not aware of any studies that have assessed motor function in SGA adolescents. Results for younger SGA children are inconsistent. One study did not find any motor problems in SGA children aged 3-5 years, ${ }^{23}$ another reported borderline significance of increased incidence of motor problems, ${ }^{24}$ and one found poorer motor skills for 7 year old SGA children than for controls. ${ }^{25}$ In our study a substantial proportion of the SGA children had motor problems at 14 years of age. These discrepancies may be due to different age groups and methods. However, Sommerfelt $e t a^{24}$ found that 
Table 5 Crude and adjusted odds ratio (OR) with $95 \%$ confidence intervals (Cl) as an estimate of the relative risk of motor problems, defined by a score below the 5th centile on the Movement assessment battery for children (Movement $A B C$ ) in two groups of low birthweight children compared with a control group

\begin{tabular}{|c|c|c|c|c|c|}
\hline & $\begin{array}{l}<5 \text { th } \\
\text { centile }\end{array}$ & $\begin{array}{l}\geqslant 5 \text { th } \\
\text { centile }\end{array}$ & $\begin{array}{l}\text { Crude OR } \\
(95 \% \mathrm{Cl})\end{array}$ & $\begin{array}{l}\text { OR }(95 \% \mathrm{Cl}) \\
\text { adjusted for } \\
\text { weight }\end{array}$ & $\begin{array}{l}\text { OR }(95 \% \mathrm{Cl}) \text { adjusted } \\
\text { for weight excluding } \\
\text { CP and low } 1 Q_{\text {est }}\end{array}$ \\
\hline \multicolumn{6}{|c|}{ Total Movement ABC score } \\
\hline VLBW $(n=50)$ & 13 & 37 & $9.3(2.5$ to 34.5$)$ & $9.5(2.5$ to 36.7$)$ & 6.2 (1.5 to 26.8$)$ \\
\hline SGA $(n=59)$ & 9 & 50 & $4.7(1.2$ to 18.4$)$ & $6.7(1.5$ to 29.3$)$ & $5.7(1.2$ to 26.7$)$ \\
\hline Control $(n=82)$ & 3 & 79 & 1.0 & 1.0 & \\
\hline \multicolumn{6}{|c|}{ Manual dexterity subscore } \\
\hline VLBW $(n=52)$ & 8 & 44 & 4.8 (1.2 to 19.0$)$ & 5.3 (1.3 to 21.8$)$ & $3.5(0.7$ to 17.1$)$ \\
\hline SGA $(n=59)$ & 11 & 48 & $6.0(1.6$ to 22.7$)$ & $10.5(2.3$ to 48.4$)$ & $9.5(1.9$ to 47.1$)$ \\
\hline Control $(n=82)$ & 3 & 79 & 1.0 & 1.0 & 1.0 \\
\hline \multicolumn{6}{|l|}{ Ball skills subscore } \\
\hline $\operatorname{VLBW}(n=51)$ & 7 & 44 & 3.1 (0.9 to 11.3$)$ & $3.2(0.8$ to 11.9$)$ & $3.1(0.8$ to 11.9$)$ \\
\hline SGA $(n=59)$ & 0 & 59 & * & * & * \\
\hline \multirow{2}{*}{\multicolumn{6}{|c|}{$\begin{array}{l}\text { Static/dynamic } \\
\text { balance subscore }\end{array}$}} \\
\hline & & & & & \\
\hline VLBW $(n=50)$ & 12 & 38 & 6.2 (1.9 to 20.6$)$ & 8.9 (2.5 to 32.4$)$ & 6.3 (1.6 to 24.5$)$ \\
\hline SGA $(n=59)$ & 7 & 52 & $2.7(0.7$ to 9.5$)$ & $4.6(1.1$ to 19.9$)$ & $4.6(1.1$ to 19.6$)$ \\
\hline Control $(n=83)$ & 4 & 79 & 1.0 & 1.0 & 1.0 \\
\hline
\end{tabular}

5 year old SGA children had lower scores than controls using the Grooved Pegboard test, which may be consistent with the increased risk of poor manual dexterity in the SGA group in our study.

The main difference in our results between VLBW and SGA children is that VLBW children have poor motor function across the continuum of the Movement ABC, while SGA children have poor manual dexterity, and poor balance after adjustment for weight. In the VLBW group, motor problems were seen for both boys and girls, while motor problems in the SGA group were found especially for boys. These findings may indicate more global impairment in VLBW children, suggesting different pathophysiological mechanisms for the motor problems in VLBW and SGA children.

A vulnerable area of the developing brain is the periventricular white matter containing the large motor tracts. Lesions in this area may be closely related to VLBW. ${ }^{37}$ The high prevalence of motor problems in the VLBW group may therefore be consistent with the previously reported high prevalence of brain lesions seen on magnetic resonance imaging in VLBW children. ${ }^{37}$

In the parasagittal region of the full term brain, vascular border zones are vulnerable to a fall in perfusion pressure which can cause subcortical necrosis. ${ }^{38}$ In SGA adolescents, a possible pathophysiological explanation for the poor manual dexterity may be perinatal circulation disturbances and hypoxia in these watershed areas, as lesions in the parasagittal region involve upper, more than lower, limbs. ${ }^{38}$

Balance was also affected in SGA adolescents after adjustment for weight. The cerebellum develops during the last months of pregnancy, ${ }^{39}$ and is involved with the coordination of motor activity and mechanisms that influence and maintain posture and equilibrium. ${ }^{38}$ Animal studies have shown that growth restriction before and after birth may result in reduced myelination and weight of the cerebellum..$^{40}{ }^{41}$ Growth restriction of the cerebellum may be responsible for both the poor balance and fine tuning of movements contributing to poor manual dexterity in SGA children.

Male fetuses have higher growth velocities than female fetuses in the third trimester, ${ }^{42-44}$ when the human brain more than doubles its weight. ${ }^{45}$ It is therefore possible that SGA boys may be more vulnerable to growth restriction during this period than girls.

Previous studies have shown that motor problems are associated with poor academic performance, ${ }^{46}{ }^{47}$ as well as emotional and social problems. ${ }^{46}$ Poor motor skills may be more problematic for these children in early adolescence, as the school curriculum introduces a wide range of new activities which may highlight their motor problems. ${ }^{20}$ Poor manual dexterity would in particular be likely to affect writing skills, ${ }^{17}$ and may be increasingly important in further education.

Table 6 Crude odds ratio (OR) with 95\% confidence intervals (CI) as an estimate of the relative risk of motor problems by sex, defined by a score below the 5th centile on Movement assessment battery for children (total $A B C$ score) in two groups of low birth weight compared with a control group

\begin{tabular}{lllllllll}
\hline Group & Sex & & \multicolumn{2}{c}{$<$ 5th centile $\%$} & ₹th centile & $\%$ & OR & 95\%Cl \\
\hline VLBW & Boys & $(n=27)$ & 7 & 25.9 & 20 & 74.1 & 11.6 & 1.3 to 100.9 \\
& Girls & $(n=23)$ & 6 & 26.1 & 17 & 73.9 & 8.1 & 1.5 to 44.2 \\
SGA & Boys & $(n=27)$ & 7 & 25.9 & 20 & 74.1 & 11.6 & 1.3 to 100.9 \\
& Girls & $(n=32)$ & 2 & 6.3 & 30 & 93.8 & 1.5 & 0.2 to 11.5 \\
\multirow{2}{*}{ Control } & Boys & $(n=34)$ & 1 & 2.9 & 33 & 97.1 & 1.0 & \\
& Girls & $(n=48)$ & 2 & 4.2 & 46 & 95.8 & 1.0 & \\
\hline
\end{tabular}

VLBW, Very low birth weight; SGA, small for gestational age. 
In conclusion, VLBW and SGA adolescents have increased risk of motor problems compared with control children. Whether this is due to prenatal, perinatal, or postnatal factors cannot be answered in this study.

\section{Authors' affiliations}

K A I Evensen, S Kulseng, A-M Brubakk, Department of Laboratory Medicine, Children's and Women's Health, Norwegian University of Science and Technology, Trondheim, Norway

T Vik, Department of Community Medicine and General Practice, Norwegian University of Science and Technology, Trondheim J Helbostad, Department of Public Health and Primary Health Care, University of Bergen, Norway

M S Indredavik, Department of Neuroscience, Norwegian University of Science and Technology, Trondheim, Norway

\section{REFERENCES}

1 McCormick MC. The contribution of low birth weight to infant mortality and childhood morbidity. N Engl J Med 1985;312:82-90.

2 Kramer MS. Determinants of low birth weight: methodological assessment and meta-analysis. Bull WHO 1987;65:663-737.

3 Hack M, Klein NK, Taylor HG. Long-term developmental outcomes of low birth weight infants. Future Child 1995;5:176-96.

4 Hack M, Fanaroff AA. Outcomes of children of extremely low birthweight and gestational age in the 1990's. Early Hum Dev 1999;53:193-218.

5 Horwood L, Mogridge N, Darlow BA. Cognitive, educational and behavioural outcomes at 7 to 8 years in a national very low birthweight cohort. Arch Dis Child Fetal Neonatal Ed 1998;79:F12-20.

6 Vohr BR, Msall ME. Neuropsychological and functional outcomes of very low birth weight infants. Semin Perinatol 1997;21:202-20.

7 McCormick MC. The outcomes of very low birth weight infants: are we asking the right questions? Pediatrics 1997:99:869-76.

8 Ornstein M, Ohlsson A, Edmonds J, et al. Neonatal follow-up of very low birthweight/extremely low birthweight infants to school age: a critical overview. Acta Paediatr Scand 1991;80:741-8.

9 Forslund M, Bierre I. Follow-up of preterm children I. Neurological assessment at 4 years of age. Early Hum Dev 1989:20:45-66.

10 Herrgard E, Luoma L, Tuppurainen $\mathrm{K}$, et al. Neurodevelopmental profile at five years of children born at $\leqslant 32$ weeks gestation. Dev Med Child Neurol 1993;35:1083-96.

11 Mutch L with the Scottish Low Birth Weight Group. The Scottish low birth weight study: outcome at $4 \frac{1}{2}$ years in a geographically defined population of children weighing less than 1750 grams at birth I. Survival, growth, neuromotor and sensory impairment. Arch Dis Child 1992;67:675-81.

12 Ong LC, Boo NY, Chandran V. Predictors of neurodevelopmental outcome of Malaysian very low birthweight children at 4 years of age. J Paediatr Child Health 2001;37:363-8.

13 Torrioli MG, Frisone MF, Bonvini L, et al. Perceptual-motor, visual and cognitive ability in very low birthweight preschool children without neonatal ultrasound abnormalities. Brain Dev 2000;22:163-8.

14 Jongmans M, Mercuri E, de Vries L, et al. Minor neurological signs and perceptual-motor difficulties in prematurely born children. Arch Dis Child Fetal Neonatal Ed 1997;76:F9-14

15 Marlow N, Roberts BL, Cooke RWI. Motor skills in extremely low birthweight children at the age of 6 years. Arch Dis Child 1989;64:839-47.

16 Marlow N, Roberts L, Cooke R. Outcome at 8 years for children with birth weights of $1250 \mathrm{~g}$ or less. Arch Dis Child 1993;68:286-90.

17 Pharoah PO, Stevenson CJ, Cooke RW, et al. Clinical and subclinical deficits at 8 years in a geographically defined cohort of low birthweight infants. Arch Dis Child 1994:70:264-70.

18 Sommerfelt K, Ellertsen B, Markestad T. Low birthweight and neuromotor development: a population based, controlled study. Acta Paediatr 1996;85:604-10.

19 Davis PG, Doyle LW, Rickards AL, et al. Methylxanthines and sensorineural outcome at 14 years in children $<1501 \mathrm{~g}$ birthweight. J Paedriatr Child Health 2000;36:47-50.
20 Powls A, Botting N, Cooke RW, et al. Motor impairment in children 12 to 13 years old with a birthweight of less than $1250 \mathrm{~g}$. Arch Dis Child Fetal Neonatal Ed 1995;73:F62-6.

21 Goldenberg RL, Hoffman HJ, Cliver SP. Neurodevelopmental outcome of small-for-gestational-age infants. Eur $J$ Clin Nutr 1998;52:54-8.

22 Hadders-Algra M, Huisjes HJ, Touwen BC. Preterm or small-for-gestationalage infants. Neurological and behavioural development at the age of 6 years. Eur J Pediatr 1988;147:460-7.

23 Low JA, Galbraith RS, Muir D, et al. Intrauterine growth retardation: a study of long-term morbidity. Am J Obstet Gynecol 1982;142:670-7.

24 Sommerfelt K, Sonnander K, Skranes J, et al. Neuropsychologic and motor function in small-for gestational preschoolers. Pediatr Neurol 2002;26:186-91.

25 Neligan GA, Kolvin I, Scott DM, et al. Born too soon or born too small: a follow-up study to seven years of age. Clinics in Developmental Medicine. London: William Heinemann Medical Books, Spastics International Medical Publications, 1976;61

26 Indredavik MS, Vik T, Heyerdahl S, et al. Psychiatric symptoms and disorders in adolescents with low birth weight. Arch Dis Child Fetal Neonatal Ed 2004:89:F445-50.

27 Henderson SE, Sugden D. Movement assessment battery for children. London: The Psychological Corporation, 1992.

28 Shrout PE, Fleiss JL. Intraclass correlations: uses in assessing rater reliability. Psychol Bull 1979;86:420-8.

29 Russman BS. Disorders of motor execution. I. cerebral palsy. In: David RB, ed. Child and adolescent neurology, Mosby's neurology psychiatry access series. Chicago: Mosby-Year Book, Inc, 1998

30 Wechsler D. Wechsler intelligence scale for children-third edition. USA: Swedish version by the Psychological Corporation, 1999.

31 Hollingshead AS. Two factor index of social status. New Haven, CT: Yale University, 1958.

32 Kleinbaum DG, Kupper LL, Morgenstern H. Epidemiologic research. New York: Van Nostrand Reinhold Company, 1982.

33 Ford GW, Doyle LW, Davis NM, et al. Very low birth weight and growth into adolescence. Arch Pediatr Adolesc Med 2000; 154:778-84.

34 Peralta-Carcelen M, Jackson DS, Goran MI, et al. Growth of adolescents who were born at extremely low birth weight without major disability. J Pediatr 2000;136:633-40

35 Powls A, Botting N, Cooke RW, et al. Growth impairment in very low birthweight children at 12 years: correlation with perinatal and outcome variables. Arch Dis Child Fetal Neonatal Ed 1996:75:F152-7.

36 Albertsson-Wikland K, Karlberg J. Postnatal growth of children born small for gestational age. Acta Paediatr Suppl 1997;423:193-5.

37 Skranes J, Nilsen G, Smevik O, et al. Cerebral MRI of very low birth weight children at 6 years of age compared with the findings at 1 year. Pediatr Radiol 1998;28:471-5.

38 Volpe JJ. Neurology of the Newborn, 4th ed. Philadelphia: WB Saunders Company, 2001.

39 Mcleary RD, Kuhns LR, Barr M. Ultrasonography of the fetal cerebellum. Radiology 1984;151:439.

40 Bourre JM, Morand C, Chanez O, et al. Influence of intrauterine malnutrition on brain development: alteration of myelination. Biol Neonate 1981;39:96-9.

41 Dobbing J, Hopewell JW, Lynch A. Vulnerability of developing brain. VII. Permanent deficit of neurons in cerebral and cerebellar cortex following early mild under-nutrition. Exp Neurol 1971;32:439-47.

42 Morales-Rosello J, Martinez-Gonzalez L, Santonja-Lucas JJ. Predicted and actual fetal weight throughout the last trimester. J Ultrasound Med 1997; 16:711-17

43 Spinillo A, Capuzzo E, Nicola S, et al. Interaction between fetal gender and risk factors for fetal growth retardation. Am J Obstet Gynecol 1994:171:1273-7.

44 Thomas $\mathrm{P}$, Peabody J, Turnier $\mathrm{V}$, et al. A new look at intrauterine growth and the impact of race, altitude, and gender. Pediatrics 2000;106:E21

45 O'Rahilly R, Müller F. Human embryology and teratology. New York: WileyLiss, 1992.

46 Losse A, Henderson SE, Elliman D, et al. Clumsiness in children: do they grow out of it? A 10-year follow-up study. Dev Med Child Neurol 1991;33:55-68.

47 Zubrick SR, Macartney H, Stanley FJ. Hidden handicap in school-age children who received neonatal intensive care. Dev Med Child Neurol 1988;30:145-52. 